\title{
Selective Functionalization of Resorcinarene Cavitands; Single Crystal X-ray Structure of a Distally Functionalized Cavitand
}

\author{
Harold Boerrigter," Willem Verboom, ${ }^{b}$ Gerrit J. van Hummel, ${ }^{c}$ Sybolt Harkema, ${ }^{c}$ and David N. Reinhoudt ${ }^{b, "}$ \\ Netherlands Energy Research Foundation (ECN)," \\ P.O. Box 1, 1755 ZG Petten, The Netherlands.
}

Laboratories of Organic Chemistry and Chemical Physics, ${ }^{\mathrm{c}}$ University of Twente, P.O. Box 217, 7500 AE Enschede, The Netherlands.

\begin{abstract}
A new method for the selective functionalization of resorcinarene cavitands is described starting from tetrakis(bromomethyl)cavitands. Copyright (-) 1996 Elsevier Science Ltd
\end{abstract}

Resorcinarene cavitands are well known macrocyclic compounds that have an enforced cavity which is formed by the rigid positioning of four aromatic units. ${ }^{1}$ In contrast to the related calix[4]arenes, ${ }^{2}$ cavitands have hardly been used for the design of receptors ${ }^{3}$ by e.g. positioning of (different) functional groups on the concave surface. This may be due to the fact that only a limited number of functional groups can directly be introduced at the aromatic rings' and only a few incidental examples are known of selective functionalization involving laborious multistep procedures."

In this communication we report our preliminary results on a new synthesis of selectively functionalized cavitands ${ }^{5}$ starting from the easily accessible tetrakis(bromomethyl)cavitands. ${ }^{6}$ This approach is based on the partial substitution of the bromine atom(s) for phthalimido groups. Due to the influence of the number of phthalimido moieties on the polarity, the different compounds can easily be separated using column chromatography. Subsequent functionalization of the unreacted bromomethyl groups creates the possibility to synthesize cavitands which contain, in addition to one or more (protected) amino groups, other functional groups.

Methyloctol 1 was synthesized in $90 \%$ yield by reaction of 2-methylresorcinol and 1-hexanal following general literature procedures. ${ }^{7}$ Subsequent reaction of octol 1 with $\mathrm{CH}_{2} \mathrm{BrCl}$ in DMF gave methylcavitand 2 in $96 \%$ yield. In our first attempts to synthesize tetrakis(bromomethyl)cavitand 3 we used the conditions reported by Sorrell and Pigge ${ }^{6}$ for the bromination of corresponding methylcavitands. However, reaction of methylcavitand 2 with 4.1 equiv of NBS in $\mathrm{CCl}_{4}$, catalyzed with benzoyl peroxide, did not result in the formation of the desired product 3. ${ }^{8}$ Upon changing the catalyst to AIBN, tetrakis(bromomethyl)cavitand 3 could be obtained in $87 \%$ yield after simple recrystallization of the crude reaction mixture from ethanol. The structure of 3 followed from 'H NMR down-field shifts of the outer bridge protons from 5.87 to $6.02 \mathrm{ppm}$, and the aromatic protons from 6.97 to $7.13 \mathrm{ppm}$, due to the introduction of the bromine atoms. Reaction of 3 with 6 equiv of potassium phthalimide in the pressence of 0.4 equiv of tributylhexadecylphosphonium bromide as phase-transfer catalyst in refluxing toluene for 4 hours, gave tetrakis(phthalimidomethyl)cavitand 4 in 74\% yield after column chromatography. The 'H NMR spectrum of 4 shows the signal for the cavitand aromatic protons at $7.05 \mathrm{ppm}$ and a doublet for the outer bridge protons at $5.76 \mathrm{ppm}$. 
When methylcavitand 3 was reacted with less than 4 equiv of potassium phthalimide, a mixture of products was obtained. Depending on the reaction conditions, besides tetrasubstituted derivative 4 , four partially functionalized products were formed: the monophthalimido- (5), the distal (or 1,3-bis)phthalimido- (6), the proximal (or 1,2-bis)phthalimido- (7), and the tris(phthalimidomethyl)cavitand 8. All products, could easily be separated using standard column chromatography $\left(\mathrm{SiO}_{2} 60\right.$; gradient hexanes/EtOAc $90 / 10$ to 60/40), ${ }^{9}$

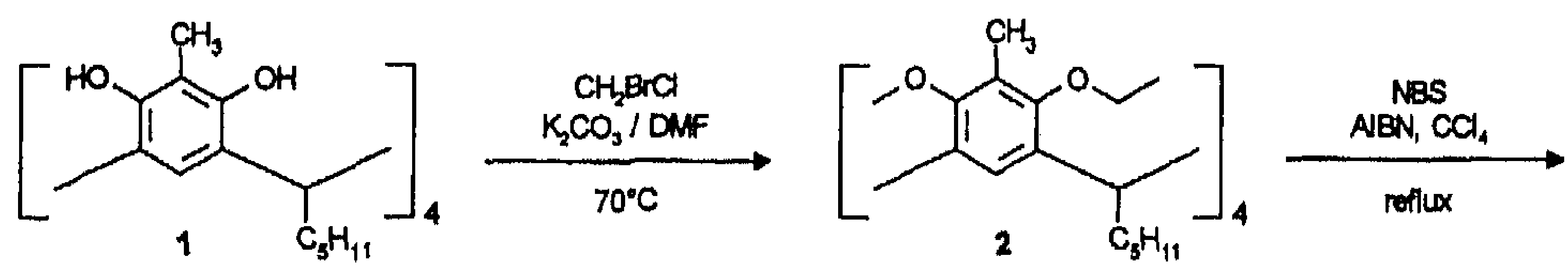<smiles>C#CCCC(C)c1cc(C)c(OCC)c(CBr)c1OCC</smiles><smiles>[R]CC1=C(C[R])C2(C[R])CC(C)CC1(C[R])CC2(C)C</smiles>

Scheme 1

$\begin{array}{ccccccccccc} & \mathrm{R}_{1} & \mathrm{R}_{2} & \mathrm{R}_{3} & \mathrm{R}_{4} & & \mathrm{R}_{1} & \mathrm{R}_{2} & \mathrm{R}_{3} & \mathrm{R}_{4} \\ \text { 4 } & \text { phth } & \text { phth } & \text { phth } & \text { phth } & \mathbf{9} & \mathrm{CN} & \mathrm{CN} & \mathrm{CN} & \text { phth } \\ \mathbf{5} & \mathrm{Br} & \mathrm{Br} & \mathrm{Br} & \text { phth } & \mathbf{1 0} & \mathrm{OMe} & \text { phth } & \mathrm{OMe} & \text { phth } \\ 6 & \mathrm{Br} & \text { phth } & \mathrm{Br} & \text { phth } & \mathbf{1 1} & \mathrm{OAc} & \mathrm{OAc} & \text { phth } & \text { phth } \\ 7 & \mathrm{Br} & \mathrm{Br} & \text { phth } & \text { phth } & \mathbf{1 2} & \mathrm{H} & \text { phth } & \text { phth } & \text { phth } \\ \mathbf{8} & \mathrm{Br} & \text { phth } & \text { phth } & \text { phth } & \mathbf{1 3} & \mathrm{H} & \mathrm{NH}_{2} & \mathrm{NH}_{2} & \mathrm{NH}_{2}\end{array}$

Compound 6 is the first example of a directly synthesized distally substituted cavitand, without the loss of functionality on the two remaining positions. Cavitand 6 can be differentiated clearly from the proximally substituted cavitand 7 by the signals for the bridge protons in the ${ }^{1} H$ NMR spectra. Due to the high degree of symmetry in 6 only one doublet is present for the (outer) bridge protons at $6.08 \mathrm{ppm}$, while the spectrum of 7 , induced by the loss of symmetry, shows three doublets (ratio 1:1:2) at 5.99,5.93, and $5.91 \mathrm{ppm}$, respectively. The structure of the distally substituted cavitand 6 was unambiguously proven by a single crystal $\mathrm{X}$-ray structure (Figure 1). ${ }^{10,11}$ In the solid state, the cavity of the cavitand is filled by the $\mathrm{CH}_{3}$-group of one alkyl chain of a neighbouring molecule, while the solvent molecules from the recrystallization $\left(\mathrm{CH}_{2} \mathrm{Cl}_{2}\right.$ and $\mathrm{CH}_{3} \mathrm{CN}$ ) occupy the space between the molecules.

When the reaction is carried out in toluene the product distribution depends statistically on the number of equivalents of potassium phthalimide added (Table 1; entries 1 and 2). This indicates that in toluene the reaction rates of the subsequent introduction of phthalimido groups are of the same order. In DMF (entry 3 ) the introduction of the second phthalimido group is slower, as can be concluded from the low yield of the disubstituted compounds 6 and 7 related to the mono- and trisubstituted cavitands 5 and 8 , respectively. The relative distribution of 6 and 7 of 1:2 is in agreement with the statistical ratio, which was also found for the reaction in toluene. In acetonitrile (entries 4 and 5) the relative distribution of 6 and 7 is 3:1, which is a complete inversion of the distribution, compared to the statistically expected ratio. This can be explained by the lower solubility, inducing partial precipitation, of 6 compared to 7, causing mainly 7 to be reacted further to the trisubstituted product 8.

In general, the yields of the partially substituted products can be influenced by (i) the solvent and, (ii) the number of potassium phthalimide equivalents. In toluene the yield of mono- and trisubstituted 
cavitands 5 and 8 is controlled by the number of potassium phthalimide equivalents added, while the solvent determines the ratio of the yields of compounds 6 and 7 .

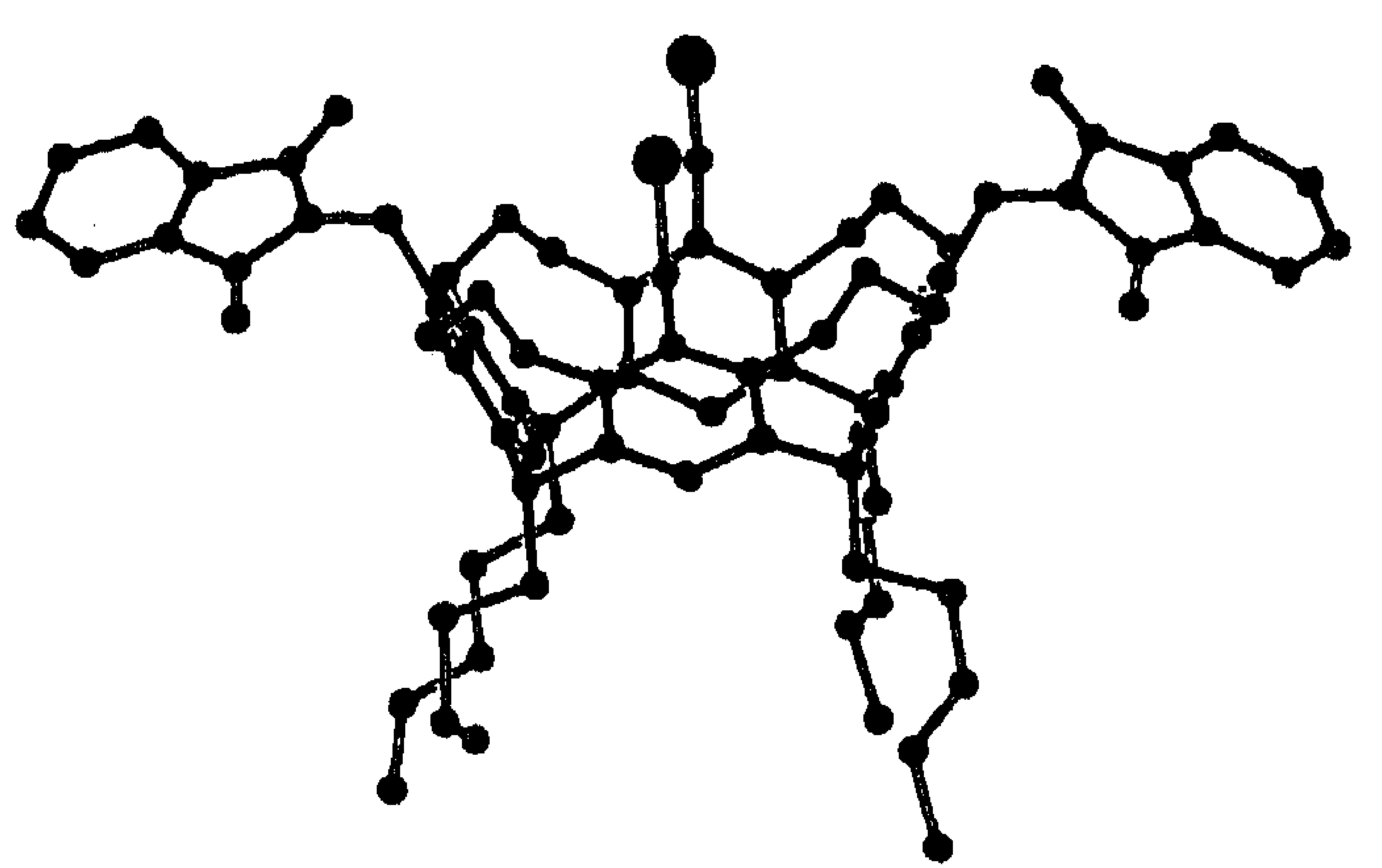

Figure 1. Single Crystal X-ray Structure of Cavitand 6.

The partially substituted cavitands 5-8 have many possible applications due to their suitability for further functionalization. This is illustrated by the synthesis of four cavitands with a second functional group besides the phthalimido moiety. The bromine atoms in 5-8 can easily be substituted (reaction of 5 with KCN in DMF gave 9 in 49\% yield, reaction of 6 with NaOMe gave 10 in 21\%, and reaction of 7 with NaOAc gave 11 in $53 \%$ yield), or they can just be removed (reaction of 8 in DMF with $\mathrm{NaBH}_{4}$ at $0^{\circ} \mathrm{C}$ or $\mathrm{NaCNBH}_{3}$ at $70^{\circ} \mathrm{C}$ afforded 12 in essentially quantitative yield). The phthalimido groups are readily removed to release the amine moieties, e.g. reaction of 12 with 30 equiv of hydrazine in refluxing ethanol/THF gave the amino derivative 13 in $89 \%$ yield.

Table 1. Product Distribution of Partially Substituted Cavitands.

\begin{tabular}{ccccccccccccc}
\hline Entry & $\begin{array}{c}3 \\
{[\mathrm{~g}]}\end{array}$ & Solvent" & $\begin{array}{c}\text { Volume } \\
{[\mathrm{mL}]}\end{array}$ & $\begin{array}{c}\text { K.phth } \\
{[\text { [equiv] }}\end{array}$ & $\begin{array}{c}\text { Time } \\
{[\text { hours] }}\end{array}$ & $\mathbf{5}$ & $\mathbf{6}$ & $\mathbf{7}$ & $\mathbf{8}$ & $\mathbf{4}$ & total \\
\hline 1 & 1.00 & toluene & 100 & 2.0 & 5 & 28 & 12 & 25 & 8 & 2 & 75 \\
2 & 0.81 & toluene & 80 & 2.4 & 17 & 7 & 8 & 20 & 37 & n.i. $^{\text {d }}$ & 72 \\
3 & 1.00 & DMF & 50 & 2.2 & 4.5 & 21 & 2 & 5 & 14 & 10 & 52 \\
4 & 1.00 & $\mathrm{CH}_{3} \mathrm{CN}$ & 100 & 2.2 & 4 & 12 & 22 & 7 & 17 & 11 & 69 \\
5 & 1.00 & $\mathrm{CH}_{3} \mathrm{CN}$ & 50 & 2.2 & 5 & 13 & 26 & 11 & 20 & 5 & 75 \\
\hline
\end{tabular}

'All reactions were performed at reflux temperature, except in DMF $\left(70^{\circ} \mathrm{C}\right)$; $^{\text {b }}$ The catalyst was used in 0.1 equiv to the potassium phthalimide; 'Isolated yield; ${ }^{d}$ n.i.: Product not isolated.

In conclusion a relatively simple route has been developed to selectively functionalized cavitands. The major advantage of this approach is the possibility to synthesize the different partially functionalized cavitands in reasonable yields, which can be influenced by varying the reaction conditions. 


\section{References and Notes}

1. For reviews see: (a) Cram, D.J.; Cram, J.M. Container Molecules and their Guests, Monographs in Supramolecular Chemistry, Vol. 4, Stoddart, J.F. (ed.), Royal Society of Chemistry: Cambridge, 1994; (b) Timmerman, P.; Verboom, W.; Reinhoudt, D.N. Tetrahedron 1996, 52, 2663.

2. For a recent review see: Böhmer, V. Angew. Chem. Int. Ed. Engl. 1995, 34; 713.

3. Cavitands have been used in combination with calixarenes for complexation of steroids: Timmerman, P.; Brinks, E.A.; Verboom, W.; Reinhoudt, D.N. J. Chem. Soc., Chem. Commun. 1995, 417.

4. (a) Timmerman, P.; Van Mook, M.G.A.; Verboom, W.; Van Hummel, G.J.; Harkema, S.; Reinhoudt, D.N. Tetrahedron Lett. 1992, 33, 3377; (b) Sorrell, T.N.; Richards, J.L. Synlett 1992, 155; (c) Robbins, T.A.; Cram, D.J. J. Chem. Soc., Chem. Commun. 1995, 1515.

5. All new compounds were characterized by ${ }^{\prime} \mathrm{H}$ and ${ }^{13} \mathrm{C}$ NMR, MS-FAB, melting point and gave satisfactory elemental analyses. Selected melting points: $9,157-159^{\circ} \mathrm{C} ; 10,148-150^{\circ} \mathrm{C} ; 11,164-166^{\circ} \mathrm{C}$; $12,155-157^{\circ} \mathrm{C} ; 13,139-141^{\circ} \mathrm{C}$. Selected ${ }^{\prime} \mathrm{H}$ NMR data of 13: $\delta 6.98\left(\mathrm{~s}, 3 \mathrm{H}, \mathrm{CH}_{3} \mathrm{ArH}\right), 6.88(\mathrm{~s}, 1 \mathrm{H}$, $\left.-\mathrm{CH}_{2} \mathrm{ArH}\right), 5.84,5.81\left(2 \mathrm{~d}, 4 \mathrm{H}\right.$, outer $\left.-\mathrm{OCH}_{2} \mathrm{O}-\right), 4.68(\mathrm{t}, 4 \mathrm{H}, \mathrm{ArCHAr}), 4.27\left(\mathrm{~d}, 4 \mathrm{H}\right.$, inner $-\mathrm{OCH}_{2} \mathrm{O}-$ ), $3.57,3.52\left(2 \mathrm{~s}, 4: 2 \mathrm{H}, \mathrm{CH}_{2} \mathrm{NH}_{2}\right), 1.89\left(\mathrm{~s}, 3 \mathrm{H}, \mathrm{ArCH}_{3}\right)$.

6. Sorrell, T.N.; Pigge, F.C. J. Org. Chem. 1993, 58, 784.

7. (a) Cram, D.J.; Karbach, S.; Kim, H.-E.; Knobler, C.B.; Maverick, E.F.; Ericson, J.L.; Helgeson, R.C. J. Am. Chem. Soc. 1988, 110, 2229. (b) Tunstad, L.M.; Tucker, J.A.; Dalcanale, E.; Weiser, J.; Bryant, J.A.; Sherman, J.C.; Helgeson, R.C.; Knobler, C.B.; Cram, D.J. J. Org. Chem. 1989, 54, 1305.

8. The 'H NMR spectrum of the reaction mixture showed multiple signals for the protons in the methyleneoxy bridges, indicating the presence of partially brominated products. Prolonging the reaction time or using up to eight equiv of NBS did not improve the outcome of the reaction. Isolation of the tetrabrominated product from the product mixture with column chromatography remained unsuccessful.

9. The partially functionalized products $\mathbf{5 - 8}$ show a decreased stability when stored on silica, in solution and/or contacted with air for a prolonged time, probably due to the loss of bromine. When stored shielded from light at $-18^{\circ} \mathrm{C}$ no decomposition occurred.

10. X-ray crystallographic analysis of 6: colorless prism, $\mathrm{C}_{72} \mathrm{H}_{76} \mathrm{Br}_{2} \mathrm{~N}_{2} \mathrm{O}_{12} \cdot \mathrm{XCH}_{3} \mathrm{CN}, \mathrm{F} . \mathrm{W}=1321.2$, monoclinic, space group $P 21 / n, a=14.180(3), b=30.67(1), \quad c=15.537(1) \AA, \quad \beta=97.10(1)^{\circ}$, $\mathrm{V}=6705(4) \AA^{3}, \mathrm{Z}=4, \mathrm{D}_{\text {calc. }}=1.39 \mathrm{~g} / \mathrm{cm}^{3}, \mathrm{~T}=130 \mathrm{~K}$. Data were collected on an Enraf-Nonius CAD4 diffractometer in the $\left(\omega-2 \theta\right.$ scan mode $\left(2.5^{\circ}<\theta<55^{\circ}\right)$, using graphite monochromated $\mathrm{Cu} \mathrm{K}_{\alpha}$ radiation, $(\lambda=1.5418 \AA)$. From the 8964 independent reflections measured, $6311\left(I_{0}>3 \sigma\left(I_{0}\right)\right)$ were used in the refinements. The crystal was rather unstable during the measurements, due to evaporation of solvent molecules $\left(\mathrm{CH}_{3} \mathrm{CN}\right)$, resulting in an increase of mosaicity. The structure was solved by direct methods using SIR $92^{11}$ and refined by full-matrix least-squares ( 829 variables). In the structure disorder was found in some of the pentane chains, affecting bond angles and distances. Furthermore a number of peaks was found in a different Fourier synthesis, which were attributed to disordered solvent atoms and refined as carbon atoms with occupancy factors of 0.5 . The resulting $R$-factors were $R=14.8 \%$, $R_{\mathrm{w}}=19.9 \%$. Thermal parameters were refined anisotropically, with the exception of those belonging to solvent atoms and a number of atoms in the disordered part of the pentane chains. H-atoms were not used in the calculations. Tables with atomic coordinates, bond lengths and angles have been deposited at the Cambridge Crystallographic Data Centre.

11. Burla, M.C.; Camalli, M.; Cascarano, G.; Giacovazzo, C.; Polidori, G.; Spagna, R.; Viterbo, D. J. Appl. Cryst. 1989, 22, 389. 